Review

\title{
Promising landscape for regulating macrophage polarization: epigenetic viewpoint
}

\author{
Dexi Zhou ${ }^{1,2, *}$, Kui Yang ${ }^{1,2, *}$, Lu Chen ${ }^{1,2}$, Wen Zhang ${ }^{1,2}$, Zhenyu Xu ${ }^{1,2}$, Jian Zuo ${ }^{1,2}$, Hui \\ Jiang ${ }^{1,2}$ and Jiajie Luan ${ }^{1,2}$ \\ 1'Laboratory of Clinical Pharmacy of Wannan Medical College, Wuhu, Anhui Province, China \\ ${ }^{2}$ Department of Pharmacy in Yijishan Hospital of Wannan Medical College, Wuhu, Anhui Province, China \\ *These authors have contributed equally to this work \\ Correspondence to: Jiajie Luan, email: Ivanjiajie757@163.com \\ Dexi Zhou, email: zhoudexiahmu@163.com
}

Keywords: macrophage polarization, microRNA, methlylation, histone modification

Received: January 25, $2017 \quad$ Accepted: March 27, $2017 \quad$ Published: April 11, 2017

Copyright: Zhou et al. This is an open-access article distributed under the terms of the Creative Commons Attribution License 3.0 (CC BY 3.0), which permits unrestricted use, distribution, and reproduction in any medium, provided the original author and source are credited.

\section{ABSTRACT}

Macrophages are critical myeloid cells with the hallmark of phenotypic heterogeneity and functional plasticity. Macrophages phenotypes are commonly described as classically-activated M1 and alternatively-activated M2 macrophages which play an essential role in the tissues homeostasis and diseases pathogenesis. Alternations of macrophage polarization and function states require precise regulation of target-gene expression. Emerging data demonstrate that epigenetic mechanisms and transcriptional factors are becoming increasingly appreciated in the orchestration of macrophage polarization in response to local environmental signals. This review is to focus on the advanced concepts of epigenetics changes involved with the macrophage polarization, including microRNAs, DNA methylation and histone modification, which are responsible for the altered cellular signaling and signature genes expression during M1 or M2 polarization. Eventually, the persistent investigation and understanding of epigenetic mechanisms in tissue macrophage polarization and function will enhance the potential to develop novel therapeutic targets for various diseases.

\section{INTRODUCTION}

Monocyte-macrophage lineage derives from myeloid precursors in bone marrow and subsequently develop as tissues-specific macrophages in response to local microenvironment signals $[1,2]$. Macrophages are heterogeneous and pleiotropic cells which can be generally polarized into M1-(classically activated) or M2-(alternatively activated) subtypes, which is a continuum of diverse functional states [3, 4]. M1 phenotype could be triggered by lipopolysaccharide (LPS) and/or interferon (IFN)- $\gamma$ andis believed to exert pro-inflammatory effects on tissue injury $[5,6]$, which have the specific markers such as inducible NO synthesase (iNOS), interleukin(IL)-12 [7, 8]. In contrast, M2 macrophages are known to be polarized by IL-4 or IL13(M2a), immune complexes (M2b), or by glucocorticoids and transforming growth factor (TGF)- $\beta$ (M2c), which could produce the M2 genes, such as genes chitinase-like protein (Ym1), found in inflammatory zone 1(Fizz1), arginase1 (Arg)-1, IL-10 and TGF- $\beta$ [9-11]. There is a documented role for M2 in both wound healing and tissue remodeling by releasing a set of anti-inflammatory products [12]. The acquisition and maintenance of macrophage M1 or M2 phenotypes in diverse diseasesdepend on various signaling molecules and pathways controlled at transcriptional and post transcriptional levels [13, 14]., Additionally, there is growing evidence showing epigenetic modifications are involved in the macrophage polarization and function partially through the mechanisms, for example transcription inhibition and chromatin remodeling $[15,16]$.

MicroRNAs(miRNAs), DNA methylation(DNAm) and histone modifications have been reported as the bestknown epigenetic markers and events in different regulatory 
networks. Firstly, miRNAs are defined as the short noncoding RNAs(ncRNAs) with about 22 nucleotides, which could posttranscriptionally lead the target-gene silencing by targeting the 3'untranslated regions (UTRs) of complementary mRNAs $[17,18]$. MiRNAs-mediated macrophage polarization is a highly conserved process and important in contributing to either M1 or M2 polarization for several pathophysiologically divergent diseases [19]. Previous studies highlights the specific roles of a miRdependent approach to manipulate the inflammation and immunity by controlling the subtle adjustment of macrophage phenotypes balance [20, 21]. Notably, DNAm is one of the best studied epigenetic regulatory system and is generally associated with transcriptional silencing. DNAm is essential for chromatin-associated gene silencing which is linked to the functions of methylated $\mathrm{CpG}$ islands [22, 23]. More recent studies using pharmacological and genetical approaches identify that DNAm is also associated with alterations in expression of M1/M2 genes [24]. Furthermore, DNAm is believed to integrate aberrant miRNAs function into multi-type molecular processes and macrophage heterogeneity. For example,the hypomethylated $\mathrm{CpG}$ sites with aberrant miRNAs are associated with monocytes aging [25]. Additionally, DNA methyltransferases1 (DNMT1)-mediated suppressors of cytokines signaling 1(SOCS1) hypermethylation, which result in the enhancement of LPS-induced pro-inflammatory cytokines expression in macrophages [26].

Finally, histone modifications are mainly thought to be the crosstalk between transcription factors and chromatinmodifying enzymes, which could function as epigenetic markers of chromatin state correlated with gene activation and repression [27]. Methods for measuring histone modifcations have identified that they associate with a variety of macrophage biological processes, including. survival, differention and activation [28-30]. Remarkably, analysis of specific histone modifications demonstrates that they serve as the predictors of $\mathrm{M} 1 / \mathrm{M} 2$ polarization through the positively and negatively regulate the M1/M2 gene expression.

In general, in this review we include insights from signature genes, cellular signals, particularly epigenetic changes including miRs, DNAm and histones modifications, to highlight the general features of these modifications in the regulation of macrophage polarization and function Here we conclude the properties of macrophage polarization and function in the context of transcriptionally and post-transcriptionally biological processes. Epigenetic factors that directly or indirectly regulate the macrophage polarization and function have been linked to many human diseases pathogenesis. Taken together, more and more evidence that epigenetic alterations are crucially molecular mechanisms in controlling macrophage heterogeneity and plasticity might provide novel therapeutic targets in the light of macrophage-based cellular approaches.

\section{MICRORNA}

Multiple miRs have been shown to be important mediators of macrophage physiological and pathological events such as proliferation, differentiation, activation and apoptosis [31-33]. Further studies indicating the alterated miRs regulatemacrophage inflammatory phenotype by targeting cellular signaling, gene expression and morphological features of macrophages [34-36]. Thus, there is a great need to identify functional miRs and find the mechanisms underlying miRs-exerted macrophage polarized effects. In conclusion, here we demonstrate the potential miRs which play central roles in the disturbance of a delicate equilibrium between the M1 and M2 profiles. We will also describe the factors that drive miRsassociated polarization of macrophages towards classically and alternatively activated phenotypes.

M1-polarized macrophage is commonly described as the pro-inflammatory cell type, which exhibit potent microbicidal properties and promote Th1 responses.

Analysis of different stimuli (LPS, oxLDLand IFN- $\gamma$ ) has identified the inflammatory miRNA(inflamma-miR) profiling in M1 polarized microglia/macrophags [37, 38]. Recent studies have revealed that many miRs play crucial roles in fine-tuning the level of M1 genes expression in different dieases, such as inflammatory diseases, rheumatoid arthritis(RA) and tumors. The pretreatment of chronic alcohol consumption augmented LPS-induced miR-155 levels in macrophages via NF- $\kappa \mathrm{B}$ and the increased miR155 contributes to alcohol-induced elevation in TNF- $\alpha$ production [39]. More recently, miR-155 knockout (KO) mice exhibited predominance of M2 phenotype when received alcohol diet for several weeks, which led to the decreased steatosis and inflammation in liver [40]. Elevated miR-155 levels are also the biomarkerof atherosclerotic lesions [41]. MiR-155 plays a pro-atherogenic role by promoting the SOCS1-STAT3-PDCD4 axis and expression of CC-chemokine ligand 2(CCL2) in M1-type macrophages, thereby enhancing vascular inflammation, plaque formation and rupture [42]. Silencing of the miR155 target gene B-cell CLL/lymphoma 6 (Bcl6) in mice harboring miR $155^{-/}$macrophages enhanced atherosclerotic plaques, and experiments performed by moxLDL/IFN- $\gamma$ induction in vitro also confirmed it [43]. Bcl6 is therefore performed as the possible antiatherosclerotic targets through the intervention of miR-155 induced M1 polarization [43, 44]. Akt1 and Akt2 conversely mediated M1 and M2 polarization with the involvement of miR-155 [45-47]. The Akt1 suppression by miR-342-5p induces proinflammatory cytokines such as IL-6 in macrophages via the upregulation of miR-155 [47]. Thus, the crosstalk of miR-342-5p and miR-155 may offer a promising strategy to treat atherosclerotic vascular disease. MiR-155 in macrophages could possibly lead to the hierarchical miRs expression at least partially due to inhibition of the transcription factor CCAAT/enhancer-binding transactivator proteins $(\mathrm{C} /$ 
EBP $\beta$ ) [48]. Both miR-155 and miR-146a are coordinately regulated the development of endotoxin tolerance via gene colocalization of $\mathrm{C} / \mathrm{EBP} \beta, \mathrm{NF}-\kappa \mathrm{B}$ with the transcriptional machinery and histone3 methylation,in macrophages [49]. Synovial membrane and synovial fluid (SF) macrophages from patients with RA display up-regulated expression of miR-155, which lead to the inhibition of Src homology 2-containing inositol phosphatase-1 (SHIP-1) in $\mathrm{CD}^{+} 8^{+}$cells [50]. In turn, miR-155 inhibits the expression of SOCS1 and may lead to the upregulation of proinflmmatory cytokines (TNF- $\alpha$ and IL-1 $\beta$ ) in macrophages of RA patients [51]. The upregulation of Notch-mediated miR-223 inhibits the aryl hydrocarbon receptor (AHR) signaling activation in $\mathrm{CD}_{14}^{+}$macrophages and increases pro-inflammatory cytokines pruduction in RA [52]. Therefore, divergent miRs--based macrophage activation and polarization may be an intriguingly therapeutic target for RA. MicroRNA-155 promotes the pathogenesis of experimental colitis through the pro-inflammatory secretions including IL-6, TNF- $\alpha$, IL-1 $\beta$, and IFN- $\gamma$ by repressing SHIP-1 expression [53]. Most importantly, miR-155 promotes the phenotypic skewing from M2 to M1 could by targeting M2-associated genes instead of M1-like genes [54], including lead to the inhibition of STAT6 by targeting IL-13R $\alpha 1$ [55] and directly repress SMAD2 expression which influence TGF- $\beta / \mathrm{Smad}$ signaling pathway in the macrophage [56]. However, miR-155 a typical multifunctional microRNA which in atherosclerosis(AS) also acts as an anti-inflammatory microRNA [57], is evidenced by hematopoietic deficiency of miR155 enhances the 'inflammatory' monocyte subset $\left(\mathrm{CD} 11 \mathrm{~b}^{+} \mathrm{Ly}_{6 \mathrm{G}} \mathrm{Ly}^{-} \mathrm{C}^{\mathrm{hi}}\right)$ and inhibits 'resident' monocytes

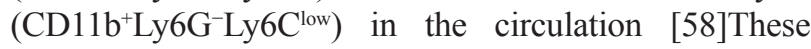
results might be explained by the appropriate activation of miR-155 is used to hold the balance between M1 and M2 macrophages in the disease pathogensis.

Many other miRs are involved in the establishment of M1 polarization. Previously, it was uncovered that miR-147 is involved in a negative-feedback loop in which TLR stimulation induces miR-147 to prevent excessive inflammatory responses in macrophages [59]. Peroxisome proliferator-activated receptor $\delta$ (PPAR $\delta$ ) is regulated by miR-9 in primary human monocytes stimulated with LPS, which is of great importance of skewing inflammatory M1-subtype [60]. M1-like macrophage is not only correlated with inflammatory diseases responses, but also is capable of involving in the invasion, migration and resolution of carcinoma. Tumorassociated macrophages (TAMs)polarization associated with the tumorigenesis is strongly relied on the wellprogrammed process of TAMs phenotype switch from an anti-tumoral M1-like phenotype to a pro-tumoral M2like phenotype in the tumor microenvironment [61, 62]. MiR-19a-3p was downregulated in RAW264.7 cells of the M2 phenotype in conditoned medium of 4T1 mouse breast tumor cells. Most importantly, overexpression of miR-19a-3p could switch the TAMs phenotype from
M2 to M1 with the consequence of downregulation of Fra-1 and it downstream genes VEGF,STAT3 and pSTAT3 [63]. Recent data highlight the anti-tumoral function of miR-155 by reprogramming the TAMs into M1-phenotype by the Akt signaling which constraining carcinogenesis [64]. Adipose tissue from obese individuals has been shown that the elevated expression of miR$125 \mathrm{~b}$ which is associated to increase M1 macrophage polarization via directly repressing interferon regulatory factor 4(IRF4) levels [65-67]. Surprisingly, mouse Raw 264.7 macrophages stimulated by LPS resulted in the upregulation of miR-155, but down-regulation of miR$125 \mathrm{~b}$ levels which was accompanied by the proper TNFaproduction [68]. Therefore, the miR-125b-mediated M1 polarization may be triggered by TNF- $\alpha$ [69]. In summary, further investigation remains necessary for the deeper understanding of macrophages acquire the M1 phenotype by specific miRs (see Figure 1).

Considerable evidence has suggested that different miRs are involved in the anti-inflammatory action via regulating immune cells functions and immune responses. Herein, we clarify the functions and mechanisms of M2associated miRs in various physiological and pathological conditions.

MiR-146a has been implicated as an essential molecule links the anti-inflammatory M2 polarization in different diseases. In systemic juvenile idiopathic arthritis (SJIA), knockdown of miR-146a promoted M1 but diminished M2 SJIA monocytes polarization by targeting INHBA [70]. Systematic studies of miR-146a functions in TAMs in breast cancer found that miR-146a enhanced the M2 molecules production and the antagomir of miR-146a transfected RAW264.7 cells inhibited 4T1 tumor growth [14].Conversely, miR-222 in TAMs suppressed 4T1 tumor growth by downregulating CXCL12 and CXCR4. Notch1 signaling is also proved to be the target of miR-146a, which promote the M2 polarization of RAW264.7 cells [71]. Akt2 suppression and miR-146a induction skew the M2 phenotype by repressing expression of IRAK-1 and TRAF6 , resulting in the attenuation of lung injury induced by acid and LPS $[72,73]$. Tumor cells migration and invasion can be largely diminished by miR-181a, which promote the M2 macrophages polarization through directly target KLF6 and $\mathrm{C} / \mathrm{EBP} \alpha$ [74].TAMs are now considered to promote tumor progression in multiple ways and the miRsmediated TAMs polarization might be necessary for the poor prognosis in tumor microenvironment. Let-7c is one of the first noted miRs, which expression is increased in alveolar macrophages from fibrotic lungs than controls and play pro-fibrogenic roles in lung. Further study demonstrate that let-7c and miR-125a-5p are expressed at a higher level in M-BMM (M2 macrophages) than in GM-BMM (M1 macrophages) and interestingly its level could be inversely changed when M-BMM converted to GM-BMM by targeting $\mathrm{C} / \mathrm{EBP}-\delta$ and $\mathrm{KLF} 13[75,76]$. Alcohol-exposed monocytes can stimulate naive monocytes to polarize into 
M2 macrophages via extracellular vesicles (EVs) and miR27 a cargo [77]. High levels of miR-27a in circulating EVs from plasma might be a potential therapeutic target for alcoholic hepatitis patients. Adipose tissue inflammation and systemic insulin resistance are more severer in miR$223 \%$ mice, which might partially due to miR-223 could suppress M1 and in favor of M2 polarization pathway in macrophages by inhibiting Pknox [78]. An increased ratio of M1/M2 type markers in spinal cord microglia/macrophages is associated with persistent hyperalgesia in $\mathrm{GRK}^{+} /^{-}$mice and reduced spinal cord microglia miR-124 levels. Then it was found that miR-124 treatment could restore the M1/M2 balance and reversed the persistent hyperalgesia by skewing the M2-like polarization via inhibiting the activation of $\mathrm{C} /$ EBP- $\alpha$ [79]. More interestingly, brain-specific miR-124 is expressed in microglia but not in peripheral macrophages, which directly inhibited the $\mathrm{C} / \mathrm{EBP} \alpha$ and its downstream target PU.1, could lead to the activated phenotype into a quiescent $\mathrm{CD} 45^{\text {low }} \mathrm{MHC}$ class $\mathrm{II}^{\text {low }}$ phenotype resembling resting microglia and suppress the experimental autoimmune encephalomyelitis (EAE) [31]. The antiinflammatory functions of miR-181a were investigated in LPS-induced Raw264.7, the results indicated that miR181a mimics significantly inhibited levels of inflammatory factors (IL-1 $\beta$, IL-6, and TNF- $\alpha$ ) at least in part by downregulating IL-1 $\alpha$ levels [80].

Increasingly studies show that the interaction of miRs and other epigenetic factors are now emerging as critical regulators in immune responses [81]. A study from Lin et al. firmly demonstrated that the activation of type I IFN (IFN-I) and downstream IFN-I receptor-JAK1STAT1 signal cascade could inhibit the expression of miR-145 in macrophages, which through directly targeting the epigenetic IL-10 gene silencer histone deacetylase 11(HDAC11) [82]. In consequence, the enhanced IL10 production lead to the suppression of inflammatory response, which might skew the macrophage to M2 phenotype $[83,84]$. The roles of other epigenetic factors in the macrophage polarization will be discussed later in this review (see Figure 2).

\section{DNA METHYLATION}

The aberrant occurrence of DNAm patterns (chemical modifications to the cytosine residues of DNA) has a significant influence on the biological behavior of macrophages $[85,86]$. This part was therefore conducted to summarize that alterations in DNAm profiles, including both hyper- and hypomethylation, with the specific emphasis on the influence present in the macrophage polarization.

The Kruppel-like transcription factor (KLF) family participates in the activation and inflammation of myeloid and lymphocyte cell lineage during immune responses [87]. KLFs have been recognized as the molecular toggles controlling macrophage polarization, including KLF6 and $10[88,89]$. KLF4 exhibits remarkable function to cooperate with STAT6 to induce an M2 genetic profile and

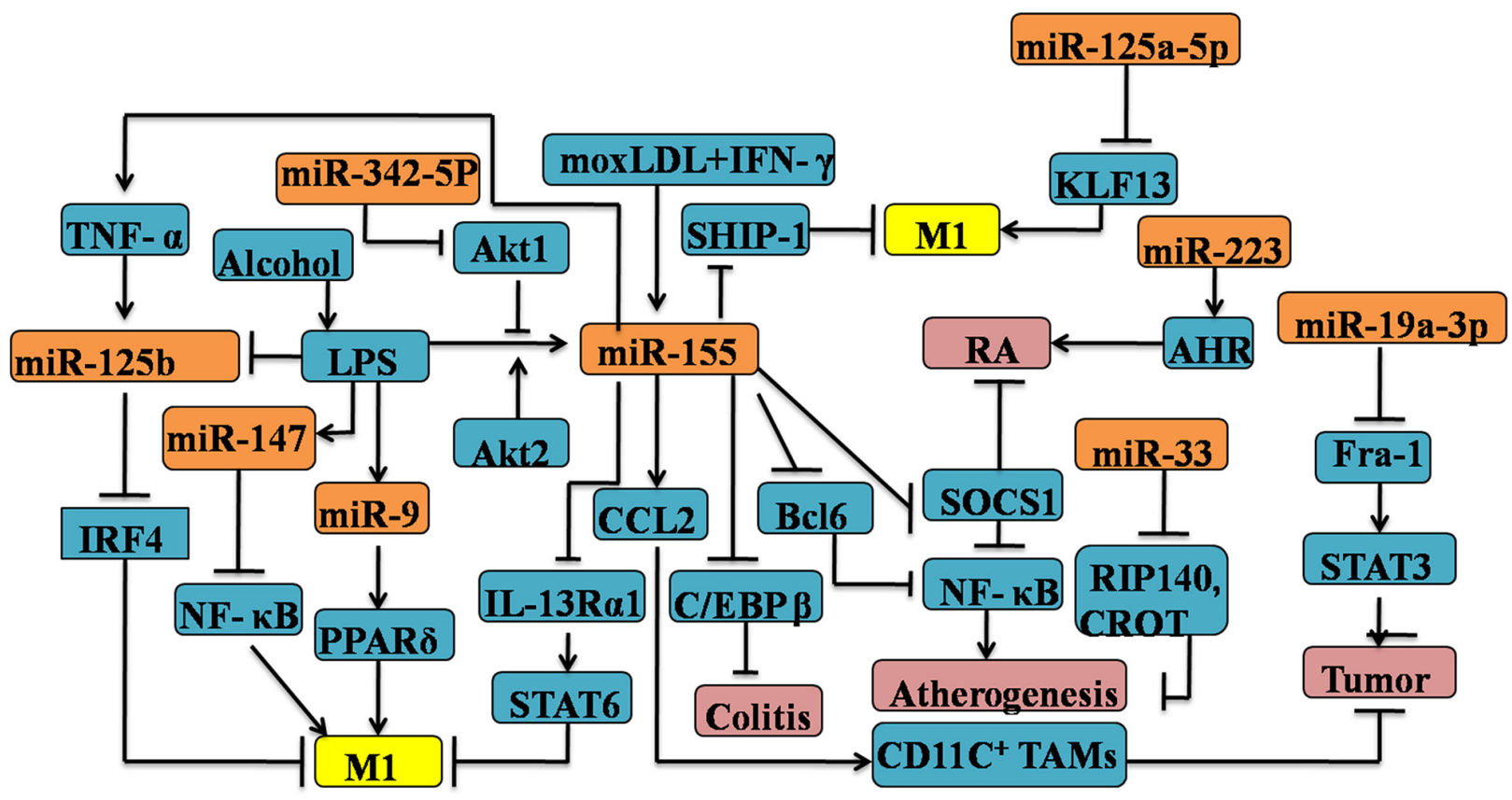

Figure 1: Regulation of M1 polarization by microRNAs in the macrophages. Several mircoRNAs, including miR-9, 19a-3p, $33,125 a-5 p, 125 b, 146 a, 147,155,223,342-5 p$ are involved in the M1 macrophage polarization by targeting the expression of various signature genes, such as $\mathrm{C} / \mathrm{REP} \beta$, SOCS-1, NF- $\kappa \mathrm{B}$. MicroRNA-mediated M1 polarization has significant implications for various diseases, for example colitis, atherogenesis and other inflammatory diseases. 
inhibit M1-type targets via sequestration of coactivators for required for NF- $\mathrm{BB}$ activation [90]. More importantly, many studies recently proposed the association between KLF4 and DNAm [91, 92]. It was involved a common principle of recognition of methylated $\mathrm{CpG}$ by $\mathrm{C} 2 \mathrm{H} 2$ zinc finger $(\mathrm{ZnF})$ proteins, involving a spatially conserved ArgGlu pair, which might be regulated by DNMT3a [91, 93]. Mechanically, KLFs are epigenetically involved in the macrophage polarization through the regulation of miRs and DNAm.

DNMTs are responsible for catalyzing epigenetic silencing and inappropriate activation of gene expression of DNAm [94]. There is novel evidence to suggest that DNMT 1, 3a and b are differentially expressed in M2 compared to M1 macrophage, which are all associated with gene silencing [95]. DNMT1mediated M1 polarization is causally linked to the development of AS by directly target the promoter of PPAR- $\gamma$ in macrophages [86]. The promoter of PPAR- $\gamma$ is binded to DNMT3b, which may contribute to the M1 adipose tissue macrophages (ATMs) polarization and inflammation [24]. Hyperhomocysteinemia (HHcy) is an independent risk factor associated with the AS and other cardiovascular events. Hcy inhibits cystathionine $\gamma$-lyase (CSE) expression and hydrogen sulfide (H2S) production by binding to the CSE promoter region through the increased DNMT1 expression and DNA hypermethylation, which may trigger the elevations of pro-inflammatory cytokines (TNF- $\alpha$, IL-1 $\beta$ ) in macrophages [96]. Lund et al. unequivocally observed that atherogenic lipoproteins (APOE) promote global DNA hypermethylation in monocyte which is the effective markers of AS [97]. Therefore, DNMT inhibition or knockdown could decrease the M1 polarization, which provides a novel strategy for the prevention and therapy of AS. In addition, treatment with DNMT inhibitor 5-Aza 2-deoxycytidine(Aza) promotes an anti-inflammatory M2 macrophage phenotype and attenuation of acute lung injury(ALI) [98]. Pharmacologically using 5-aza or genetically by DNMT1 deletion inhibits PPAR $\gamma$ promoter DNAm and promotes M2 macrophage activation, which protected from the obesity-induced inflammation and insulin resistance [99]. Curcumin ameliorates experimental autoimmune myocarditis

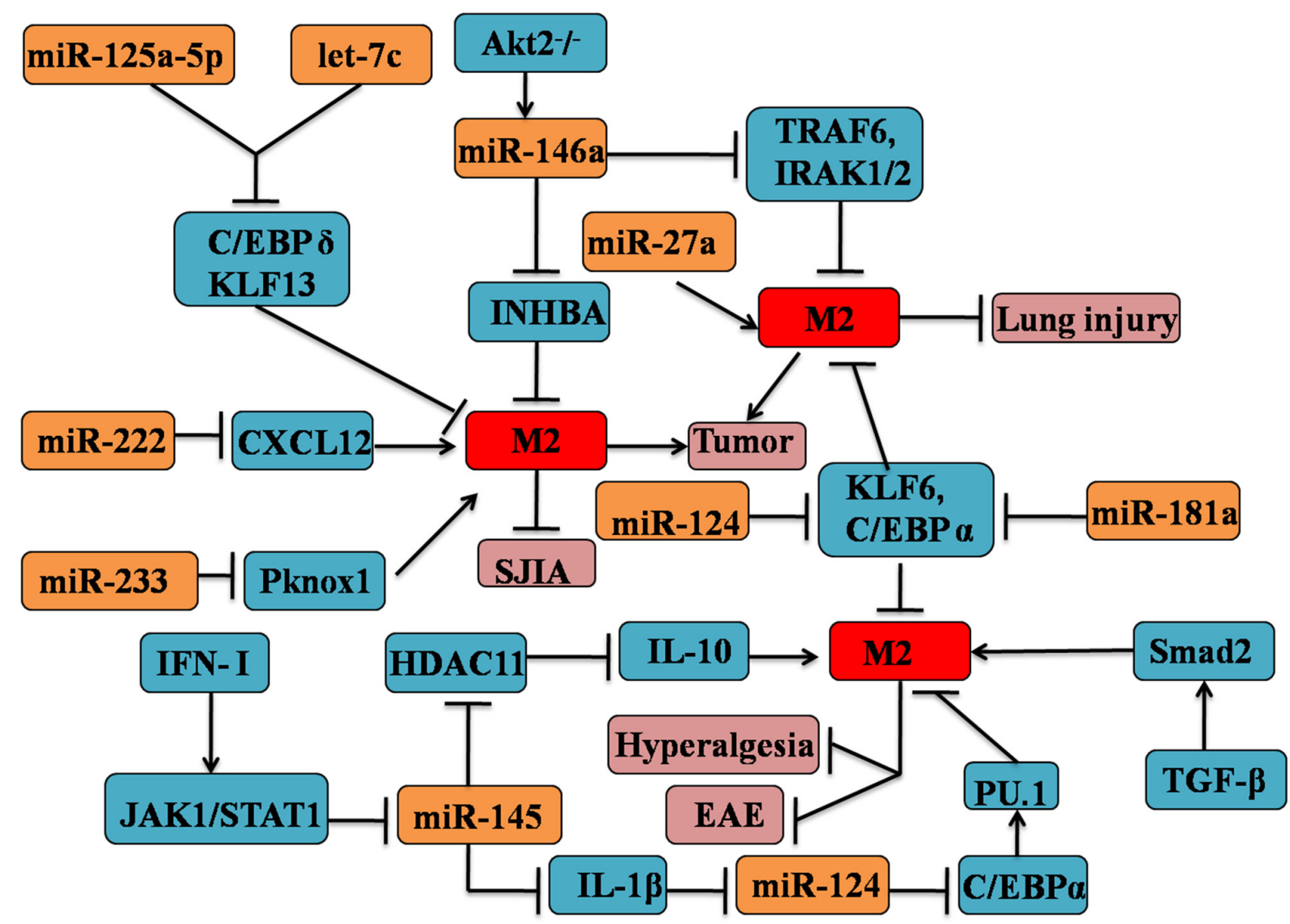

Figure 2: MicroRNAs are involved in the regulation of $\mathrm{M} 2$ macrophages phenotypic and functional polarization. MicroRNAs (inculding let-7c, miR-27a, 124,145, 146a, 155, 181a, 124, 222 and 233) could contribute to the M2 macrophage polarization. MicroRNA-induced M2 polarization mainly depends on the interaction with cytokines signaling and transcription factors pathway, such as TGF- $\beta$, IL-10, STAT1, C/EBP $\alpha$. 
(EAM) by activating STAT6 and inducing M2 polarization of macrophages through a possible way by which inhibits DNMT [100]. Consequently, these data clearly demonstrate that DNA hypermethylation of multiple genes serves as $\mathrm{s}$ a critical determinant of macrophage polarization, which contributes to the development of many inflammatory diseases. It is important to note that the expression of DNMT3a and DNMT3al are increased significantly in M2 compared to M1macrophages, which is dramatically associated with AMPK-signaling [101]. Conversely, DNMT3b was significantly lower in M2 vs M1 adipose macrophages. Moreover, up-regulation of galectin-3 production is the characteristic of M2-like macrophage [102]. Galectin-3 ablation in tumor stroma and parenchyma could induce the M1-like TAMs and decrease angiogenesis through disturbing the responses of macrophages to the interdependent VEGF and TGF- $\beta 1$ signaling pathways [103]. Furthermore, through the DNA methylation analysis by the bisulfate genome sequencing method [104], the loss of galectin-3 of associated with its promoter methlation which could be inhibited by the treatment of 5-aza. Given the mentioned statements it is therefore might exist a negative feedback loop between M2-like macrophage and galectin-3. Dysregulated bone morphogenetic proteins (BMP) may also contribute to the macrophage polarization [105]. The initiation and progression of renal cell carcinoma ( $\mathrm{RCC}$ ) is promoted by BMP-6-mediated IL-10 expression, which regulates M2 polarization. Another BMP, BMP-2 is also involved in controlling M2 macrophage by the regulation of jumonji domain containing-3 (Jmjd3), a histone 3 Lys27 (H3K27) demethylase [106]. And lovastatin was shown to inhibit DNMT activity in vitro, resulting in the demethylation of the BMP2 promoter region [107, 108]. Some other interplay between DNA methylation and histone modification in the macrophage polarization will be discussed later in this review (see Figure 3).

\section{HISTONE MODIFICATION}

Epigenetic traits are tightly regulated by the major epigenetic modification: histone proteins associated with DNA (histone modifications). Histones may undergo divergent epigenetic changes, including methylation, acetylation, phosphorylation, ubiquitylation and SUMOylation, which are often involved in establishing patterns of gene dysregulation associated with altered chromatin states, leading to gene activation and gene

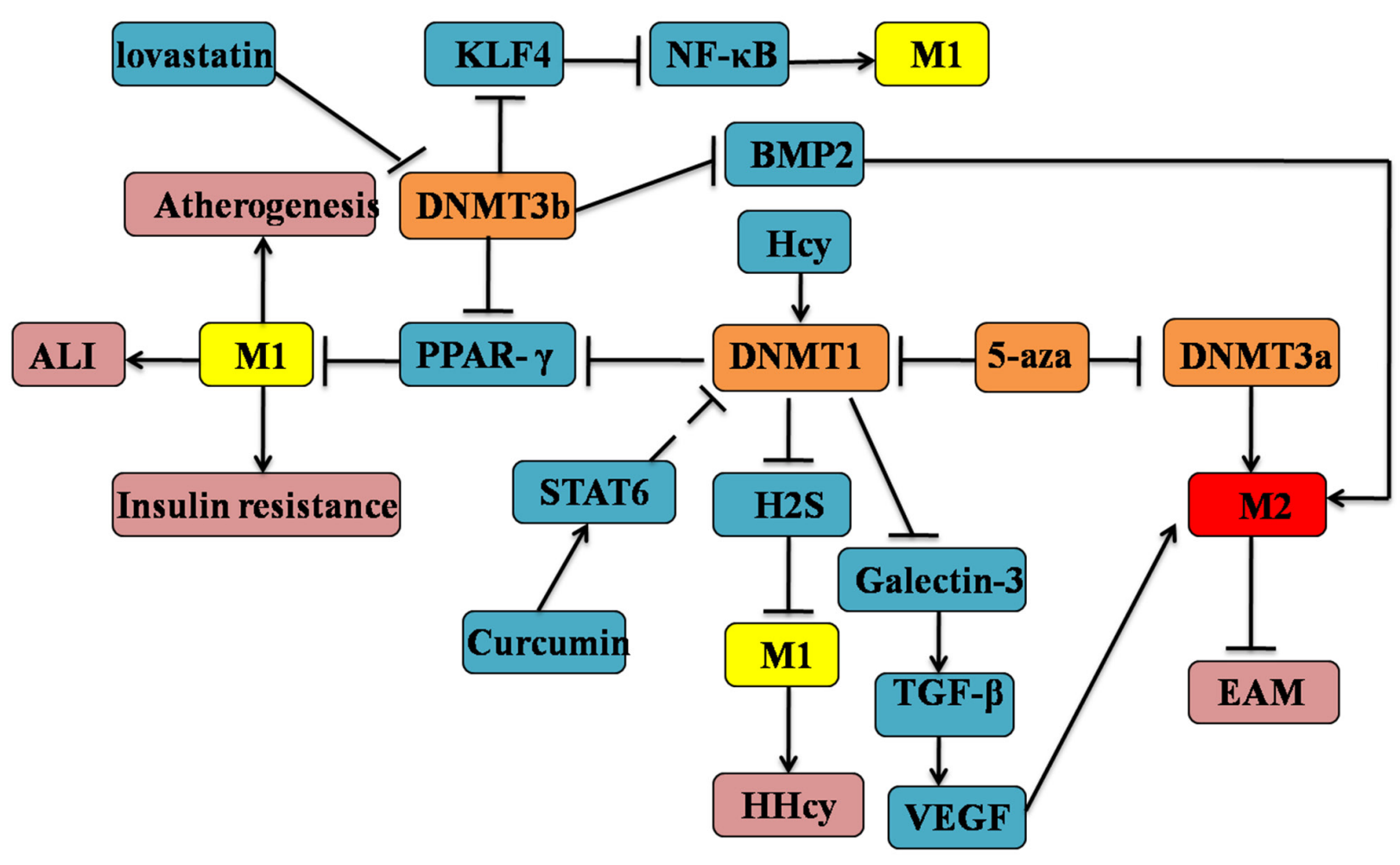

Figure 3: DNA methylation in the determination of macrophages M1/M2 polarization. Firstly, DNMTs are responsible for catalyzing epigenetic silencing and inappropriate activation of gene expression involved with the macrophage phenotypic changes. Then, DNMTs (including DNMT1, 3a and 3b) are differentially expressed in M1 or M2 macrophages, which might play opposite roles in the $\mathrm{M} 1 / \mathrm{M} 2$ polarization. For example, the activation of DNMT1/3 might lead to the M1 polarization by targeting KLF4 and NF- $\mathrm{kB}$ signaling, which could be inhibited by 5-aza. Conversely, it inhibits the M2 macrophage polarization via the disturbance of the TGF- $\beta$ and VEGF signaling. Among this complex process, STAT6 and other genes also participate in it. 
silencing in a host of diseases [109-111]. In this part, we particularly focus on the latest advances in the field of the histones modifications profiles associated with the regulation of macrophages polarization to M1 or M2 phenotypes.

Expressions of multiple genes encoding enzymes are responsible for catalyzing and modifying various histones post-translational modifications, such as methyltransferases, demethylases, acetyltransferases and deacetylases, which are differentially expressed in M1/M2 statuses [112, 113]. Emerging findings have suggested the existence of new regulatory epigenetic-based macrophage polarization mechanisms of histones modifications in inflammation and immune regulation. As the result of the devoid of tri-methylated H3K27 in IL-4-induced M2 macrophages, human CCL1 gene is selectively targeted by aryl hydrocarbon receptor (AhR) [114]. Proinflammatory cytokines (TNF- $\alpha$ and IL-6) promoters have a histone 3 lysine 4- and H3K36 dimethylation effect by the specific methyltransferase SET and MYND domaincontaining 2 (Smyd2), which can lead to the decreased M1 polarization and NF- $\mathrm{KB}$ and ERK signaling [115]. Histone modification of increased levels of $\mathrm{H} 3$ at $\mathrm{TNF}-\alpha$ gene locus was similarly concomitant with the activation of M1 polarization and M1-related chemokines and cytokines in the low-level laser therapy (LLLT) of human THP-1 monocytes [116]. Collectively, histones modifications of genes required for M1 or M2 polarization might have the therapeutic potential in various pathologies. For example, emodin seemingly to bidirectionally restore macrophage M1/M2 polarization and immune homeostasis by inhibiting the removal of $\mathrm{H} 3 \mathrm{~K} 27$ trimethylation (H3K27me3) and the addition of H3K27 acetylation (H3K27ac), respectively [117]. Ornithine decarboxylase (ODC) could inhibit gastric and colonic inflammation by the deletion of M1 macrophage responses, which accompanied by the decreased $\mathrm{H} 3 \mathrm{~K} 4$ monomethylation, $\mathrm{H} 3 \mathrm{~K} 9$ acetylation and increased $\mathrm{H} 3 \mathrm{~K} 9$ di/trimethylation in primary macrophages [113]. As early stated, Jmjd3 is indispensable for M2 macrophage polarization in response to helminth infection and chitin, which depend on the demethylase activity of Jmjd3, lead to the inhibition of trimethylation of $\mathrm{H} 3 \mathrm{~K} 27$ by targeting a key transcription factor, IRF 4 [106]. Of note, Jmjd3-IRF4 axis was also essential for M2 microglia polarization [118], which therefore play a pivotal role in the reprogramming and

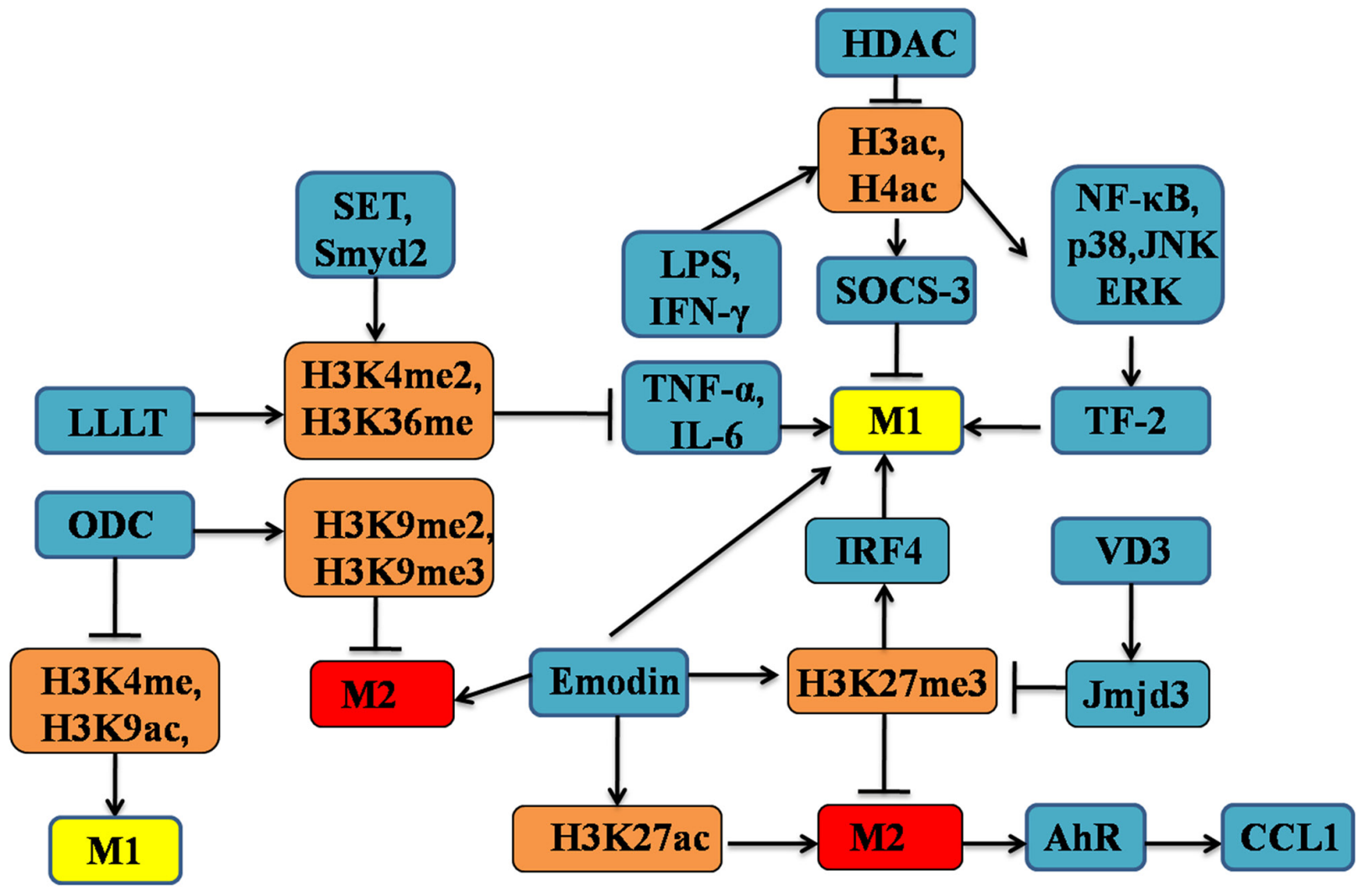

Figure 4: The altered patterns of histone modifications in the regulation of M1/M2 macrophages polarization. Epigenetic regulation of histone modifications patterns, such as methylation, and acetylation, could drive macrophage polarization into either M1 or M2 phenotype. Of note, many genes are associated with histone modifications-dependent macrophage polarization, including Jmjd3 and MAPKs. These genes could cooperate with HDACs, HATs and other proteins, which exerting important effects on macrophage polarization and function. 
maintenance of microglia phenotypes that may contribute to the immune pathogenesis of Parkinson's disease (PD). In keep with these results, demethylation of $\mathrm{H} 3 \mathrm{~K} 27 \mathrm{me} 3$ in the nuclear factor-activated T cells (NFAT) c1 (Nfatc1) gene locus by Jmjd3, playing important roles in NF- $\mathrm{BB}$ ligand (RANKL)-induced osteoclast differentiation [119]. Conversely, Jmjd3 is the transcription factor NF- $\mathrm{BB}$ dependent induced in response to microbial stimuli, and Jmjd 3 modifies the transcriptional output of LPS-activated macrophages in an H3K27 demethylation-independent manner [120].

Histone acetyltransferases (HATs) andHDACs mediate the acetylation and deacetylation for histone lysine,respectively. Histone $\mathrm{H} 3$ and $\mathrm{H} 4$ acetylation were found to be strongly associated with developmental stage of human monocytes and regulated the TNF- $\alpha$ promoter [121] Loss of HDAC function has been strongly linked to inhibition of several inflammatory diseases [122]. Monocytes polarized by IFN- $\gamma$ increased histone H4 acetylation at the TNF- $\alpha$ promoter via the ERK and p38 mitogen-activated protein kinases (MAPKs) signaling pathyways, lead to the durable effects on the activation of transcription factor-2 (TF-2) and M1 polarization [123]. Noticeably, previous findings have identified that SOCS3 as a modulator of M2 macrophage polarization [124]. LPS-induced STAT-3 and MAPKs activation, including ERK1/2, JNK, p38 pathways, combination with the acetylation of histones $\mathrm{H} 3$ and $\mathrm{H} 4$ on the SOCS-3 promoter, eliciting critical roles in SOCS-3 expression, which provides for feedback attenuation of cytokine-induced immune and inflammatory responses in macrophages and microglia [125]. Histone acetylationmediated SOCS-3 production might be involved in the macrophage polarized status. HDAC3-deficient macrophages were unable to activate almost half of the inflammatory gene expression profiles when stimulated with LPS, which resulted of decreased expression of IFN- $\beta$ and Cox-1 [126]. Thus, the inhibitor of HDACs has a causative role in developing as anti-inflammatory agents. In consistent, M2-like macrophage activation is mediated by the HDAC3 by targeting PU.1 promoter region [127]. The macrophage lacking of HDAC3 displays a phenotype similar to IL-4 stimulation and thereby ameliorate many inflammatory diseases, such as pulmonary inflammation $[127,128]$.

Finally, secretion of some bioactive substances in a signal- and context-specific manner could influence macrophage polarization by targeting histone modifications [126]. For example, vitamin D3 (VD3) interacts with the signalling of transcription factors, also participates in the macrophage activation and polarization as the immunosuppressor [129, 130]. Most importantly, the VD3 exerts an ample regulatory effect on the expression of HDACs, such as Jmjd3, involved in epigenetic regulation that may mediate its actions on gene transcription and macrophage phenotype [131]. In summary, the relationships between histone modifications and macrophage polarization have significant implications for understanding the mosaic patterns of macrophage heterogeneity as well as function (see Figure 4).

\section{CONCLUDING REMARKS}

Recent data highlight how some other epigenetic changes impact macrophage functional responses and M1/M2 polarization, influencing the immune homeostasis in response to infection and inflammation. Long non-coding RNAs(lncRNAs) expression profiles are significantly altered in macrophages exposure to differently incubated conditions, which evokes the distinct M1/M2 functional responses [132]. Of note, lncRNA MALAT1-overexpressed mesenchymal stem cells (MSCs) supernatants may serve to promote the M2 macrophage polarization, which may enhance the immunosuppressive properties of MSCs in vivo [133]. The crosstalk of lncRNA and other epigenetic manner could determine the macrophage phenotypes. SNHG14 promoted the microglia cells (MCs) classical activation by the inhibition of miR145-5p, which resulted in the high levels of TNF- $\alpha$ and $\mathrm{NO}$ in MCs during cerebral infarction [134, 135]. In conclusion, the underlying epigenetic mechanisms of macrophage polarization and function might be indicative of functional association. Macrophage-dependent inflammatory responses are considered a pivotal biological process and remain to be fully elucidated, which contributes to fit the therapeutic requirement of antiviral, antibacterial or antitumor immunity in a host of diseases.

\section{Abbreviations}

MAPKs, mitogen-activated protein kinases; miRs, microRNAs; DNAm, DNA methylation; ncRNAs, non-coding RNAs; UTRs, untranslated regions; PPAR, peroxisome proliferator-activated receptor; CCL, CCchemokine ligand; Bcl6, B-cell CLL/lymphoma 6; STAT, signal transducers and activators of transcription; AP1, activator protein-1; C/EBP, CAAT/enhancer-binding proteins; SOCS, suppressor of cytokine signaling ; PBMC, peripheral blood monocytes; TLR, toll-like receptors; TAMs, tumor-associated macrophages; iNOS, inducible nitric oxide synthase ; IRF, interferon regulatory factors; SJIA, juvenile idiopathic arthritis; EVs, extracellular vesicles; 5-Aza, 5-Aza 2-deoxycytidine; EAE, experimental autoimmune encephalomyelitis; Ym1, geneschitinase-like protein; Fizz1, found in inflammatory zone 1 ; TGF- $\beta$, transforming growth factor- $\beta$; HHcy, hyperhomocysteinemia; CSE, cystathionine $\gamma$-lyase; H2S, hydrogen sulfide; DNMT, DNA methyltransferases; H3K27, histone 3 Lys27; TF, transcription factor; HATs, histone acetyltransferases; HDACs, histone deacetylases; RANKL, nuclear factor-kB ligand; ALI, acute lung 
injury;KLF, Krüppel-like transcription factor; Jmjd3, jumonji domain containing-3 ; LLLT, low-level laser therapy; ODC, ornithine decarboxylase.

\section{ACKNOWLEDGMENTS}

All the authors contributed to the concept, design, and writing of this paper. DXZ and JJL contributed to the concept and design of the figures and tables. All authors read, reviewed and approved the final manuscript. This work was supported by grants from Science Foundation of Anhui province(NO:KJ2014A262); Foundatin for Young Talents in College of Anhui province (NO:2010SQRL175); Cultivation fund project of key scientific research of Wannan Medical College (NO:WK2013ZF02).

\section{CONFLICTS OF INTEREST}

The authors declare no conflict of interest.

\section{REFERENCES}

1. Geissmann F, Manz MG, Jung S, Sieweke MH, Merad M, Ley K. Development of monocytes, macrophages, and dendritic cells. Science. 2010; 327:656-661.

2. Horwood NJ. Macrophage polarization and bone formation: a review. Clin Rev Allergy Immunol. 2016; 51:79-86.

3. Nahrendorf M, Swirski FK. Monocyte and macrophage heterogeneity in the heart. Circ Res. 2013; 112:1624-1633.

4. Jimenez-Garcia L, Herranz S, Higueras MA, Luque A, Hortelano S. Tumor suppressor ARF regulates tissue microenvironment and tumor growth through modulation of macrophage polarization. Oncotarget. 2016; 7:6683566850. doi: 10.18632/oncotarget.11652.

5. Sindrilaru A, Peters T, Wieschalka S, Baican C, Baican A, Peter H, Hainzl A, Schatz S, Qi Y, Schlecht A, Weiss JM, Wlaschek M, Sunderkotter C, Scharffetter-Kochanek K. An unrestrained proinflammatory M1 macrophage population induced by iron impairs wound healing in humans and mice. J Clin Invest. 2011; 121:985-997.

6. Tosello-Trampont AC, Krueger P, Narayanan S, Landes SG, Leitinger N, Hahn YS. NKp46(+) natural killer cells attenuate metabolism-induced hepatic fibrosis by regulating macrophage activation in mice. Hepatology. 2016; 63:799-812

7. Enderlin Vaz da Silva Z, Lehr HA,Velin D. In vitro and in vivo repair activities of undifferentiated and classically and alternatively activated macrophages. Pathobiology. 2014; 81:86-93.

8. Laoui D, Van Overmeire E, Di Conza G, Aldeni C, Keirsse J, Morias Y, Movahedi K, Houbracken I, Schouppe E, Elkrim Y. Tumor hypoxia does not drive differentiation of tumor-associated macrophages but rather fine-tunes the M2-like macrophage population. Cancer Res. 2014; 74:24-30.

9. Feriotti C, Loures FV, Frank de Araujo E, da Costa TA, Calich VL. Mannosyl-recognizing receptors induce an M1-like phenotype in macrophages of susceptible mice but an M2-like phenotype in mice resistant to a fungal infection. PLoS One. 2013; 8:e54845.

10. Munitz A, Brandt EB, Mingler M, Finkelman FD, Rothenberg ME. Distinct roles for IL-13 and IL-4 via IL-13 receptor alpha1 and the type II IL-4 receptor in asthma pathogenesis. Proc Natl Acad Sci U S A. 2008; 105:7240-7245.

11. Sica A, Schioppa T, Mantovani A, Allavena P. Tumourassociated macrophages are a distinct M2 polarised population promoting tumour progression: potential targets of anti-cancer therapy. Eur J Cancer. 2006; 42:717-727.

12. Hallowell RW, Collins SL, Craig JM, Zhang Y, Oh M, Illei PB, Chan-Li Y, Vigeland CL, Mitzner W, Scott AL, Powell JD, Horton MR. mTORC2 signalling regulates M2 macrophage differentiation in response to helminth infection and adaptive thermogenesis. Nat Commun. 2017; $8: 14208$

13. Dai M, Wu L, He Z, Zhang S, Chen C, Xu X, Wang P, Gruzdev A, Zeldin DC, Wang DW. Epoxyeicosatrienoic acids regulate macrophage polarization and prevent LPS-induced cardiac dysfunction. J Cell Physiol. 2015; 230:2108-2119.

14. Li Y, Zhao L, Shi B, Ma S, Xu Z, Ge Y, Liu Y, Zheng D, Shi J. Functions of miR-146a and miR-222 in tumor-associated macrophages in breast cancer. Sci Rep. 2015; 5:18648.

15. Takeuch O, Akira S. Epigenetic control of macrophage polarization. Eur J Immunol. 2011; 41:2490-2493.

16. Zhang W, Liu H, Liu W, Liu Y, Xu J. Polycomb-mediated loss of microRNA let-7c determines inflammatory macrophage polarization via PAK1-dependent NF-kappaB pathway. Cell Death Differ. 2015; 22:287-297.

17. Lardenoije R, Iatrou A, Kenis G, Kompotis K, Steinbusch HW, Mastroeni D, Coleman P, Lemere CA, Hof PR, van den Hove DL, Rutten BP. The epigenetics of aging and neurodegeneration. Prog Neurobiol. 2015; 131:21-64.

18. Shan Q, Zheng G, Zhu A, Cao L, Lu J, Wu D, Zhang Z, Fan S, Sun C, Hu B, Zheng Y. Epigenetic modification of miR-10a regulates renal damage by targeting CREB1 in type 2 diabetes mellitus. Toxicol Appl Pharmacol. 2016; 306:134-143.

19. Melton DW, Lei X, Gelfond JA, Shireman PK. Dynamic macrophage polarization-specific miRNA patterns reveal increased soluble VEGF receptor 1 by miR-125a-5p inhibition. Physiol Genomics. 2016; 48:345-360.

20. Ouimet M, Ediriweera HN, Gundra UM, Sheedy FJ, Ramkhelawon B, Hutchison SB, Rinehold K, van Solingen C, Fullerton MD, Cecchini K, Rayner KJ, Steinberg GR, Zamore PD, et al. MicroRNA-33-dependent regulation of 
macrophage metabolism directs immune cell polarization in atherosclerosis. J Clin Invest. 2015; 125:4334-4348.

21. Wu XQ, Dai Y, Yang Y, Huang C, Meng XM, Wu BM, Li $\mathrm{J}$. Emerging role of microRNAs in regulating macrophage activation and polarization in immune response and inflammation. Immunology. 2016; 148:237-248.

22. Schubeler D. Function and information content of DNA methylation. Nature. 2015; 517:321-326.

23. Chiappinelli KB, Strissel PL, Desrichard A, Li H, Henke C, Akman B, Hein A, Rote NS, Cope LM, Snyder A, Makarov V, Budhu S, Slamon DJ, et al. Inhibiting DNA methylation causes an interferon response in cancer via dsRNA including endogenous retroviruses. Cell. 2016; 164:1073.

24. Yang X, Wang X, Liu D, Yu L, Xue B, Shi H. Epigenetic regulation of macrophage polarization by DNA methyltransferase 3b. Mol Endocrinol. 2014; 28:565-574.

25. Tserel L, Limbach M, Saare M, Kisand K, Metspalu A, Milani L, Peterson P. CpG sites associated with NRP1, NRXN2 and miR-29b-2 are hypomethylated in monocytes during ageing. Immun Ageing. 2014; 11:1.

26. Cheng C, Huang C, Ma TT, Bian EB, He Y, Zhang L, Li J. SOCS1 hypermethylation mediated by DNMT1 is associated with lipopolysaccharide-induced inflammatory cytokines in macrophages. Toxicol Lett. 2014; 225:488-497.

27. Benveniste D, Sonntag HJ, Sanguinetti G, Sproul D. Transcription factor binding predicts histone modifications in human cell lines. Proc Natl Acad Sci U S A. 2014; 111:13367-13372.

28. Gross TJ, Kremens K, Powers LS, Brink B, Knutson T, Domann FE, Philibert RA, Milhem MM, Monick MM. Epigenetic silencing of the human NOS2 gene: rethinking the role of nitric oxide in human macrophage inflammatory responses. J Immunol. 2014; 192:2326-2338.

29. Lawrence T, Natoli G. Transcriptional regulation of macrophage polarization: enabling diversity with identity. Nat Rev Immunol. 2011; 11:750-761.

30. Rai MN, Balusu S, Gorityala N, Dandu L, Kaur R. Functional genomic analysis of Candida glabratamacrophage interaction: role of chromatin remodeling in virulence. PLoS Pathog. 2012; 8:e1002863.

31. Ponomarev ED, Veremeyko T, Barteneva N, Krichevsky AM, Weiner HL. MicroRNA-124 promotes microglia quiescence and suppresses EAE by deactivating macrophages via the C/EBP-alpha-PU.1 pathway. Nat Med. 2011; 17:64-70.

32. Meng QL, Liu F, Yang XY, Liu XM, Zhang X, Zhang C, Zhang ZD. Identification of latent tuberculosis infectionrelated microRNAs in human U937 macrophages expressing Mycobacterium tuberculosis Hsp16.3. BMC Microbiol. 2014; 14:37.

33. Ghorpade DS, Leyland R, Kurowska-Stolarska M, Patil SA, Balaji KN. MicroRNA-155 is required for Mycobacterium bovis BCG-mediated apoptosis of macrophages. Mol Cell Biol. 2012; 32:2239-2253.

34. Graff JW, Dickson AM, Clay G, McCaffrey AP, Wilson ME. Identifying functional microRNAs in macrophages with polarized phenotypes. J Biol Chem. 2012; 287:21816-21825.

35. Ponomarev ED, Veremeyko T, Weiner HL. MicroRNAs are universal regulators of differentiation, activation, and polarization of microglia and macrophages in normal and diseased CNS. Glia. 2013; 61:91-103.

36. Zhang Y, Zhang M, Zhong M, Suo Q, Lv K. Expression profiles of miRNAs in polarized macrophages. Int J Mol Med. 2013; 31:797-802.

37. Cunha C, Gomes C, Vaz AR, Brites D. Exploring new inflammatory biomarkers and pathways during LPS-induced M1 polarization. Mediators Inflamm. 2016; 2016:6986175.

38. Li XF, Wang Y, Zheng DD, Xu HX, Wang T, Pan M, Shi JH, Zhu JH. M1 macrophages promote aortic valve calcification mediated by microRNA-214/TWIST1 pathway in valvular interstitial cells. Am J Transl Res. 2016; 8:5773-5783.

39. Bala S, Marcos M, Kodys K, Csak T, Catalano D, Mandrekar P, Szabo G. Up-regulation of microRNA-155 in macrophages contributes to increased tumor necrosis factor \{alpha\} (TNF $\{$ alpha\}) production via increased mRNA half-life in alcoholic liver disease. J Biol Chem. 2011; 286:1436-1444.

40. Bala S, Csak T, Saha B, Zatsiorsky J, Kodys K, Catalano D, Satishchandran A, Szabo G. The pro-inflammatory effects of miR-155 promote liver fibrosis and alcohol-induced steatohepatitis. J Hepatol. 2016; 64:1378-1387.

41. Wei Y, Nazari-Jahantigh M, Neth P, Weber C, Schober A. MicroRNA-126,-145, and -155: a therapeutic triad in atherosclerosis? Arterioscler Thromb Vasc Biol. 2013; 33:449-454.

42. Ye J, Guo R, Shi Y, Qi F, Guo C, Yang L. miR-155 regulated inflammation response by the SOCS1-STAT3-PDCD4 axis in atherogenesis. Mediators Inflamm. 2016; 2016:8060182.

43. Nazari-Jahantigh M, Wei Y, Noels H, Akhtar S, Zhou Z, Koenen RR, Heyll K, Gremse F, Kiessling F, Grommes J, Weber C, Schober A. MicroRNA-155 promotes atherosclerosis by repressing Bcl6 in macrophages. J Clin Invest. 2012; 122:4190-4202.

44. Zeng Q, Tao X, Huang F, Wu T, Wang J, Jiang X, Kuang $Z$, Cheng B. Overexpression of miR-155 promotes the proliferation and invasion of oral squamous carcinoma cells by regulating BCL6/cyclin D2. Int J Mol Med. 2016; 37:1274-1280.

45. Xu F, Kang Y, Zhang H, Piao Z, Yin H, Diao R, Xia J, Shi L. Akt1-mediated regulation of macrophage polarization in a murine model of Staphylococcus aureus pulmonary infection. J Infect Dis. 2013; 208:528-538.

46. Arranz A, Doxaki C, Vergadi E, Martinez de la Torre Y, Vaporidi K, Lagoudaki ED, Ieronymaki E, Androulidaki A, Venihaki M, Margioris AN, Stathopoulos EN, Tsichlis PN, 
Tsatsanis C. Akt1 and Akt2 protein kinases differentially contribute to macrophage polarization. Proc Natl Acad Sci U S A. 2012; 109:9517-9522.

47. Wei Y, Nazari-Jahantigh M, Chan L, Zhu M, Heyll K, Corbalan-Campos J, Hartmann P, Thiemann A, Weber C, Schober A. The microRNA-342-5p fosters inflammatory macrophage activation through an Akt1- and microRNA155-dependent pathway during atherosclerosis. Circulation. 2013; 127:1609-1619.

48. Dueck A, Eichner A, Sixt M, Meister G. A miR-155dependent microRNA hierarchy in dendritic cell maturation and macrophage activation. FEBS Lett. 2014; 588:632-640.

49. Doxaki C, Kampranis SC, Eliopoulos AG, Spilianakis C, Tsatsanis C. Coordinated regulation of miR-155 and miR146a genes during induction of endotoxin tolerance in macrophages. J Immunol. 2015; 195:5750-5761.

50. Kurowska-Stolarska M, Alivernini S, Ballantine LE, Asquith DL, Millar NL, Gilchrist DS, Reilly J, Ierna M, Fraser AR, Stolarski B. MicroRNA-155 as a proinflammatory regulator in clinical and experimental arthritis. Proc Natl Acad Sci U S A. 2011; 108:11193-11198.

51. Li X, Tian F, Wang F. Rheumatoid arthritis-associated microRNA-155 targets SOCS1 and upregulates TNFalpha and IL-1beta in PBMCs. Int J Mol Sci. 2013; 14:23910-23921.

52. Ogando J, Tardaguila M, Diaz-Alderete A, Usategui A, Miranda-Ramos V, Martinez-Herrera DJ, de la Fuente L, Garcia-Leon MJ, Moreno MC, Escudero S, Canete JD, Toribio ML, Cases I, et al. Notch-regulated miR-223 targets the aryl hydrocarbon receptor pathway and increases cytokine production in macrophages from rheumatoid arthritis patients. Sci Rep. 2016; 6:20223.

53. Lu ZJ, Wu JJ, Jiang WL, Xiao JH, Tao KZ, Ma L, Zheng P, Wan R, Wang XP. MicroRNA-155 promotes the pathogenesis of experimental colitis by repressing SHIP-1 expression. World J Gastroenterol. 2017; 23:976-985.

54. Ruggiero T, Trabucchi M, De Santa F, Zupo S, Harfe BD, McManus MT, Rosenfeld MG, Briata P, Gherzi R. LPS induces $\mathrm{KH}$-type splicing regulatory protein-dependent processing of microRNA-155 precursors in macrophages. FASEB J. 2009; 23:2898-2908.

55. Martinez-Nunez RT, Louafi F, Sanchez-Elsner T. The interleukin 13 (IL-13) pathway in human macrophages is modulated by microRNA-155 via direct targeting of interleukin 13 receptor alpha1 (IL13Ralpha1). J Biol Chem. 2011; 286:1786-1794.

56. Louafi F, Martinez-Nunez RT, Sanchez-Elsner T. MicroRNA-155 targets SMAD2 and modulates the response of macrophages to transforming growth factor\{beta\}. J Biol Chem. 2010; 285:41328-41336.

57. Li X, Kong D, Chen H, Liu S, Hu H, Wu T, Wang J, Chen W, Ning Y, Li Y, Lu Z. miR-155 acts as an antiinflammatory factor in atherosclerosis-associated foam cell formation by repressing calcium-regulated heat stable protein 1. Sci Rep. 2016; 6:21789.

58. Donners MM, Wolfs IM, Stoger LJ, van der Vorst EP, Pottgens CC, Heymans S, Schroen B, Gijbels MJ, de Winther MP. Hematopoietic miR155 deficiency enhances atherosclerosis and decreases plaque stability in hyperlipidemic mice. PLoS One. 2012; 7:e35877.

59. Liu G, Friggeri A, Yang Y, Park YJ, Tsuruta Y, Abraham E. miR-147, a microRNA that is induced upon tolllike receptor stimulation, regulates murine macrophage inflammatory responses. Proc Natl Acad Sci U S A. 2009; 106:15819-15824.

60. Thulin P, Wei T, Werngren O, Cheung L, Fisher RM, Grander D, Corcoran M, Ehrenborg E. MicroRNA-9 regulates the expression of peroxisome proliferatoractivated receptor delta in human monocytes during the inflammatory response. Int J Mol Med. 2013; 31:1003-1010.

61. Zhang M, He Y, Sun X, Li Q, Wang W, Zhao A, Di W. A high M1/M2 ratio of tumor-associated macrophages is associated with extended survival in ovarian cancer patients. J Ovarian Res. 2014; 7:19.

62. Engstrom A, Erlandsson A, Delbro D, Wijkander J. Conditioned media from macrophages of M1, but not M2 phenotype, inhibit the proliferation of the colon cancer cell lines HT-29 and CACO-2. Int J Oncol. 2014; 44:385-392.

63. Yang J, Zhang Z, Chen C, Liu Y, Si Q, Chuang TH, Li N, Gomez-Cabrero A, Reisfeld RA, Xiang R, Luo Y. MicroRNA-19a-3p inhibits breast cancer progression and metastasis by inducing macrophage polarization through downregulated expression of Fra-1 proto-oncogene. Oncogene. 2014; 33:3014-3023.

64. Zonari E, Pucci F, Saini M, Mazzieri R, Politi LS, Gentner B, Naldini L. A role for miR-155 in enabling tumorinfiltrating innate immune cells to mount effective antitumor responses in mice. Blood. 2013; 122:243-252.

65. McClelland AD, Kantharidis P. microRNA in the development of diabetic complications. Clin Sci. 2014; 126:95-110.

66. Ortega FJ, Moreno-Navarrete JM, Pardo G, Sabater M, Hummel M, Ferrer A, Rodriguez-Hermosa JI, Ruiz B, Ricart W, Peral B, Fernandez-Real JM. MiRNA expression profile of human subcutaneous adipose and during adipocyte differentiation. PLoS One. 2010; 5:e9022.

67. Chaudhuri AA, So AY, Sinha N, Gibson WS, Taganov KD, O'Connell RM, Baltimore D. MicroRNA-125b potentiates macrophage activation. J Immunol. 2011; 187:5062-5068.

68. Tili E, Michaille JJ, Cimino A, Costinean S, Dumitru CD, Adair B, Fabbri M, Alder H, Liu CG, Calin GA, Croce CM. Modulation of miR-155 and miR-125b levels following lipopolysaccharide/TNF-alpha stimulation and their possible roles in regulating the response to endotoxin shock. J Immunol. 2007; 179:5082-5089. 
69. Parisi C, Arisi I, D'Ambrosi N, Storti A, Brandi R, D'Onofrio M, Volonté C. Dysregulated microRNAs in amyotrophic lateral sclerosis microglia modulate genes linked to neuroinflammation. Cell Death Dis. 2013; 4:e959.

70. Li D, Duan M, Feng Y, Geng L, Li X, Hang W. MiR-146a modulates macrophage polarization in systemic juvenile idiopathic arthritis by targeting INHBA. Mol Immunol. 2016; 77:205-212.

71. Huang C, Liu XJ, QunZhou, Xie J, Ma TT, Meng XM, Li J. MiR-146a modulates macrophage polarization by inhibiting Notch1 pathway in RAW264.7 macrophages. Int Immunopharmacol. 2016; 32:46-54.

72. Vergadi E, Vaporidi K, Theodorakis EE, Doxaki C, Lagoudaki E, Ieronymaki E, Alexaki VI, Helms M, Kondili E, Soennichsen B, Stathopoulos EN, Margioris AN, Georgopoulos D, Tsatsanis C. Akt2 deficiency protects from acute lung injury via alternative macrophage activation and miR-146a induction in mice. J Immunol. 2014; 192:394-406.

73. Zeng Z, Gong H, Li Y, Jie K, Ding C, Shao Q, Liu F, Zhan Y, Nie C, Zhu W, Qian K. Upregulation of miR-146a contributes to the suppression of inflammatory responses in LPS-induced acute lung injury. Exp Lung Res. 2013; 39:275-282.

74. Bi J, Zeng X, Zhao L, Wei Q, Yu L, Wang X, Yu Z, Cao Y, Shan F, Wei M. miR-181a induces macrophage polarized to M2 phenotype and promotes M2 macrophage-mediated tumor cell metastasis by targeting KLF6 and C/EBPalpha. Mol Ther Nucleic Acids. 2016; 5:e368.

75. Banerjee S, Xie N, Cui H, Tan Z, Yang S, Icyuz M, Abraham E, Liu G. MicroRNA let-7c regulates macrophage polarization. J Immunol. 2013; 190:6542-6549.

76. Banerjee S, Cui H, Xie N, Tan Z, Yang S, Icyuz M, Thannickal VJ, Abraham E, Liu G. miR-125a-5p regulates differential activation of macrophages and inflammation. $\mathrm{J}$ Biol Chem. 2013; 288:35428-35436.

77. Saha B, Momen-Heravi F, Kodys K, Szabo G. MicroRNA cargo of extracellular vesicles from alcohol-exposed monocytes signals naive monocytes to differentiate into M2 macrophages. J Biol Chem. 2016; 291:149-159.

78. Zhuang G, Meng C, Guo X, Cheruku PS, Shi L, Xu H, Li H, Wang G, Evans AR, Safe S, Wu C, Zhou B. A novel regulator of macrophage activation: miR-223 in obesityassociated adipose tissue inflammation. Circulation. 2012; 125:2892-2903.

79. Willemen HL, Huo XJ, Mao-Ying QL, Zijlstra J, Heijnen CJ, Kavelaars A. MicroRNA-124 as a novel treatment for persistent hyperalgesia. J Neuroinflammation. 2012; 9:143.

80. Xie W, Li M, Xu N, Lv Q, Huang N, He J, Zhang Y. MiR181a regulates inflammation responses in monocytes and macrophages. PLoS One. 2013; 8:e58639.

81. Shu Y, Hu Q, Long H, Chang C, Lu Q, Xiao R. Epigenetic variability of $\mathrm{CD} 4+\mathrm{CD} 25+$ tregs contributes to the pathogenesis of autoimmune diseases. Clin Rev Allergy Immunol. 2017; 52:260-272.

82. Lin L, Hou J, Ma F, Wang P, Liu X, Li N, Wang J, Wang Q, Cao X. Type I IFN inhibits innate IL-10 production in macrophages through histone deacetylase 11 by downregulating microRNA-145. J Immunol. 2013; 191:3896-3904.

83. Qi L, Yu H, Zhang Y, Zhao D, Lv P, Zhong Y, Xu Y. IL-10 secreted by M2 macrophage promoted tumorigenesis through interaction with JAK2 in glioma. Oncotarget. 2016; 7:71673-71685. doi: 10.18632/oncotarget.12317.

84. Ambade A, Satishchandran A, Saha B, Gyongyosi B, Lowe P, Kodys K, Catalano D, Szabo G. Hepatocellular carcinoma is accelerated by NASH involving M2 macrophage polarization mediated by hif-1alphainduced IL-10. Oncoimmunology. 2016; 5:e1221557.

85. Barnawi J, Jersmann H, Haberberger R, Hodge S, Meech R. Reduced DNA methylation of sphingosine-1 phosphate receptor 5 in alveolar macrophages in COPD: a potential link to failed efferocytosis. Respirology. 2017; 22:315-321.

86. Yu J, Qiu Y, Yang J, Bian S, Chen G, Deng M, Kang H, Huang L. DNMT1-PPARgamma pathway in macrophages regulates chronic inflammation and atherosclerosis development in mice. Sci Rep. 2016; 6:30053.

87. Kim GD, Das R, Goduni L, McClellan S, Hazlett LD, Mahabeleshwar GH. Kruppel-like factor 6 promotes macrophage-mediated inflammation by suppressing B cell leukemia/lymphoma 6 expression. J Biol Chem. 2016; 291:21271-21282.

88. Zhang W, Wang X, Xia X, Liu X, Suo S, Guo J, Li M, Cao W, Cai Z, Hui Z, Subramaniam M, Spelsberg TC, Wang J, Wang L. Klf10 inhibits IL-12p40 production in macrophage colony-stimulating factor-induced mouse bone marrowderived macrophages. Eur J Immunol. 2013; 43:258-269.

89. Date D, Das R, Narla G, Simon DI, Jain MK, Mahabeleshwar GH. Kruppel-like transcription factor 6 regulates inflammatory macrophage polarization. J Biol Chem. 2014; 289:10318-10319.

90. Liao X, Sharma N, Kapadia F, Zhou G, Lu Y, Hong H, Paruchuri K, Mahabeleshwar GH, Dalmas E, Venteclef N, Flask CA, Kim J, Doreian BW, et al. Kruppel-like factor 4 regulates macrophage polarization. J Clin Invest. 2011; 121:2736-2749.

91. Liu Y, Olanrewaju YO, Zheng Y, Hashimoto H, Blumenthal RM, Zhang X, Cheng X. Structural basis for Klf4 recognition of methylated DNA. Nucleic Acids Res. 2014; 42:4859-4867.

92. Dehne N, Brune B. Hypoxic inhibition of JMJD3 reduces H3K27me3 demethylation and induction of the STAT6 target gene CCL18. Biochim Biophys Acta. 2016; 1859:1490-1501.

93. Pawlak M, Jaenisch R. De novo DNA methylation by Dnmt3a and Dnmt3b is dispensable for nuclear 
reprogramming of somatic cells to a pluripotent state. Genes Dev. 2011; 25:1035-1040.

94. Chin HG, Ponnaluri VK, Zhang G, Esteve PO, Schaus SE, Hansen U, Pradhan S. Transcription factor LSFDNMT1 complex dissociation by FQI1 leads to aberrant DNA methylation and gene expression. Oncotarget. 2016; 7:83627-83640. doi: 10.18632/oncotarget.13271.

95. Kittan NA, Allen RM, Dhaliwal A, Cavassani KA, Schaller M, Gallagher KA, Carson WF, Mukherjee S, Grembecka J, Cierpicki T, Jarai G, Westwick J, Kunkel SL, Hogaboam $\mathrm{CM}$. Cytokine induced phenotypic and epigenetic signatures are key to establishing specific macrophage phenotypes. PLoS One. 2013; 8:e78045.

96. Li JJ, Li Q, Du HP, Wang YL, You SJ, Wang F, Xu XS, Cheng J, Cao YJ, Liu CF, Hu LF. Homocysteine triggers inflammatory responses in macrophages through inhibiting CSE-H2S signaling via DNA hypermethylation of CSE promoter. Int J Mol Sci. 2015; 16:12560-12577.

97. Lund G, Andersson L, Lauria M, Lindholm M, Fraga MF, Villar-Garea A, Ballestar E, Esteller M, Zaina S. DNA methylation polymorphisms precede any histological sign of atherosclerosis in mice lacking apolipoprotein E. J Biol Chem. 2004; 279:29147-29154.

98. Thangavel J, Samanta S, Rajasingh S, Barani B, Xuan YT, Dawn B, Rajasingh J. Epigenetic modifiers reduce inflammation and modulate macrophage phenotype during endotoxemia-induced acute lung injury. J Cell Sci. 2015; 128:3094-3105.

99. Wang X, Cao Q, Yu L, Shi H, Xue B, Shi H. Epigenetic regulation of macrophage polarization and inflammation by DNA methylation in obesity. JCI Insight. 2016; 1:e87748.

100. Gao S, Zhou J, Liu N, Wang L, Gao Q, Wu Y, Zhao Q, Liu P, Wang S, Liu Y, Guo N, Shen Y, Wu Y, Yuan Z. Curcumin induces M2 macrophage polarization by secretion IL-4 and/ or IL-13. J Mol Cell Cardiol. 2015; 85:131-139.

101. Sang Y, Brichalli W, Rowland RR, Blecha F. Genome-wide analysis of antiviral signature genes in porcine macrophages at different activation statuses. PLoS One. 2014; 9:e87613.

102. MacKinnon AC, Farnworth SL, Hodkinson PS, Henderson NC, Atkinson KM, Leffler H, Nilsson UJ, Haslett C, Forbes SJ, Sethi T. Regulation of alternative macrophage activation by galectin-3. J Immunol. 2008; 180:2650-2658.

103. Machado CM, Andrade LN, Teixeira VR, Costa FF, Melo CM, Dos Santos SN, Nonogaki S, Liu FT, Bernardes ES, Camargo AA, Chammas R. Galectin-3 disruption impaired tumoral angiogenesis by reducing VEGF secretion from TGFbeta1induced macrophages. Cancer Med. 2014; 3:201-214.

104. Cokus SJ, Feng S, Zhang X, Chen Z, Merriman B, Haudenschild CD, Pradhan S, Nelson SF, Pellegrini M, Jacobsen SE. Shotgun bisulphite sequencing of the Arabidopsis genome reveals DNA methylation patterning. Nature. 2008; 452:215-219.

105. Lee JH, Lee GT, Woo SH, Ha YS, Kwon SJ, Kim WJ, Kim IY. BMP-6 in renal cell carcinoma promotes tumor proliferation through IL-10-dependent M2 polarization of tumor-associated macrophages. Cancer Res. 2013; 73:3604-3614.

106. Satoh T, Takeuchi O, Vandenbon A, Yasuda K, Tanaka Y, Kumagai Y, Miyake T, Matsushita K, Okazaki T, Saitoh T, Honma K, Matsuyama T, Yui K, et al. The Jmjd3-Irf4 axis regulates M2 macrophage polarization and host responses against helminth infection. Nat Immunol. 2010; 11:936-944.

107. Kodach LL, Jacobs RJ, Voorneveld PW, Wildenberg ME, Verspaget HW, van Wezel T, Morreau H, Hommes DW, Peppelenbosch MP, van den Brink GR, Hardwick JC. Statins augment the chemosensitivity of colorectal cancer cells inducing epigenetic reprogramming and reducing colorectal cancer cell 'stemness' via the bone morphogenetic protein pathway. Gut. 2011; 60:1544-1553.

108. Zanette DL, van Eggermond MC, Haasnoot G, van den Elsen PJ. Simvastatin reduces CCL2 expression in monocyte-derived cells by induction of a repressive CCL2 chromatin state. Hum Immunol. 2014; 75:10-14.

109. Zhang X, Li B, Rezaeian AH, Xu X, Chou PC, Jin G, Han F, Pan BS, Wang CY, Long J, Zhang A, Huang CY, Tsai FJ, et al. $\mathrm{H} 3$ ubiquitination by NEDD4 regulates $\mathrm{H} 3$ acetylation and tumorigenesis. Nat Commun. 2017; 8:14799.

110. Yu L, Fang F, Dai X, Xu H, Qi X, Fang M, Xu Y. MKL1 defines the H3K4Me3 landscape for NF-kappaB dependent inflammatory response. Sci Rep. 2017; 7:191.

111. Swatek KN, Komander D. Ubiquitin modifications. Cell Res. 2016; 26:399-422.

112. Ahmed M, de Winther MP, Van den Bossche J. Epigenetic mechanisms of macrophage activation in type 2 diabetes. Immunobiology. 2016 Sep 3. doi: 10.1016/j. imbio.2016.08.011. [Epub ahead of print].

113. Hardbower DM, Asim M, Luis PB, Singh K, Barry DP, Yang C, Steeves MA, Cleveland JL, Schneider C, Piazuelo MB, Gobert AP, Wilson KT. Ornithine decarboxylase regulates M1 macrophage activation and mucosal inflammation via histone modifications. Proc Natl Acad Sci U S A. 2017; 114:E751-E760.

114. Liao WT, Lu JH, Wang WT, Hung CH, Sheu CC, Huang SK. Epigenetic synergism between interleukin-4 and arylhydrocarbon receptor in human macrophages. J Mol Med. 2017; 95:395-404.

115. Xu G, Liu G, Xiong S, Liu H, Chen X, Zheng B. The histone methyltransferase Smyd2 is a negative regulator of macrophage activation by suppressing interleukin 6 (IL-6) and tumor necrosis factor alpha (TNF-alpha) production. $\mathrm{J}$ Biol Chem. 2015; 290:5414-5423.

116. Chen CH, Wang CZ, Wang YH, Liao WT, Chen YJ, Kuo $\mathrm{CH}$, Kuo HF, Hung CH. Effects of low-level laser therapy on M1-related cytokine expression in monocytes via histone modification. Mediators Inflamm. 2014; 2014:625048.

117. Iwanowycz S, Wang J, Altomare D, Hui Y, Fan D. Emodin bidirectionally modulates macrophage polarization and 
epigenetically regulates macrophage memory. J Biol Chem. 2016; 291:11491-11503.

118. Tang Y, Li T, Li J, Yang J, Liu H, Zhang X, Le W. Jmjd3 is essential for the epigenetic modulation of microglia phenotypes in the immune pathogenesis of Parkinson's disease. Cell Death Differ. 2014; 21:369-80.

119. Yasui T, Hirose J, Aburatani H, Tanaka S. Epigenetic regulation of osteoclast differentiation. Ann N Y Acad Sci. 2011; 1240:7-13.

120. De Santa F, Narang V, Yap ZH, Tusi BK, Burgold T, Austenaa L, Bucci G, Caganova M, Notarbartolo S, Casola S, Testa G, Sung WK, Wei CL, Natoli G. Jmjd3 contributes to the control of gene expression in LPS-activated macrophages. EMBO J. 2009; 28:3341-3352.

121. Lee JY, Kim NA, Sanford A, Sullivan KE. Histone acetylation and chromatin conformation are regulated separately at the TNF-alpha promoter in monocytes and macrophages. J Leukoc Biol. 2003; 73:862-871.

122. Shakespear MR, Halili MA, Irvine KM, Fairlie DP, Sweet MJ. Histone deacetylases as regulators of inflammation and immunity. Trends Immunol. 2011; 32:335-343.

123. Garrett S, Dietzmann-Maurer K, Song L, Sullivan KE. Polarization of primary human monocytes by IFN-gamma induces chromatin changes and recruits RNA Pol II to the TNF-alpha promoter. J Immunol. 2008; 180:5257-5266.

124. Qin H, Holdbrooks AT, Liu Y, Reynolds SL, Yanagisawa LL, Benveniste EN. SOCS3 deficiency promotes M1 macrophage polarization and inflammation. J Immunol. 2012; 189:3439-3448.

125. Qin H, Roberts KL, Niyongere SA, Cong Y, Elson $\mathrm{CO}$, Benveniste EN. Molecular mechanism of lipopolysaccharide-induced SOCS-3 gene expression in macrophages and microglia. J Immunol. 2007; 179:5966-5976.

126. Chen X, Barozzi I, Termanini A, Prosperini E, Recchiuti A, Dalli J, Mietton F, Matteoli G, Hiebert S, Natoli G. Requirement for the histone deacetylase Hdac3 for the inflammatory gene expression program in macrophages. Proc Natl Acad Sci U S A. 2012; 109:E2865-2874.
127. Mullican SE, Gaddis CA, Alenghat T, Nair MG, Giacomin PR, Everett LJ, Feng D, Steger DJ, Schug J, Artis D. Histone deacetylase 3 is an epigenomic brake in macrophage alternative activation. Genes Dev. 2011; 25:2480-2488.

128. Barnes P, Adcock I, Ito K. Histone acetylation and deacetylation: importance in inflammatory lung diseases. Eur Respir J. 2005; 25:552-563.

129. Allavena P, Signorelli M, Chieppa M, Erba E, Bianchi G, Marchesi F, Olimpio CO, Bonardi C, Garbi A, Lissoni A, de Braud F, Jimeno J, D'Incalci M. Anti-inflammatory properties of the novel antitumor agent yondelis (trabectedin): inhibition of macrophage differentiation and cytokine production. Cancer Res. 2005; 65:2964-2971.

130. Martinez FO, Gordon S, Locati M, Mantovani A. Transcriptional profiling of the human monocyte-tomacrophage differentiation and polarization: new molecules and patterns of gene expression. J Immunol. 2006; 177:7303-7311.

131. Pereira F, Barbáchano A, Singh PK, Campbell MJ, Muñoz A, Larriba MJ. Vitamin D has wide regulatory effects on histone demethylase genes. Cell Cycle. 2012; 11:1081-1089.

132. Huang Z, Luo Q, Yao F, Qing C, Ye J, Deng Y, Li J. Identification of differentially expressed long non-coding RNAs in polarized macrophages. Sci Rep. 2016; 6:19705.

133. Li X, Song Y, Liu F, Liu D, Miao H, Ren J, Xu J, Ding L, Hu Y, Wang Z, Hou Y, Zhao G. Long non-coding RNA MALAT1 promotes proliferation, angiogenesis and immunosuppressive properties of mesenchymal stem cells by inducing VEGF and IDO. J Cell Biochem. 2017 Feb 8. doi: $10.1002 /$ jcb.25927. [Epub ahead of print].

134. Qi X, Shao M, Sun H, Shen Y, Meng D, Huo W. Long noncoding RNA SNHG14 promotes microglia activation by regulating miR-145-5p/PLA2G4A in cerebral infarction. Neuroscience. 2017; 348:98-106.

135. Farrow AL, Rana T, Mittal MK, Misra S, Chaudhuri G. Leishmania-induced repression of selected non-coding RNA genes containing B-box element at their promoters in alternatively polarized M2 macrophages. Mol Cell Biochem. 2011; 350:47-57. 